\title{
Intima-Media Thickness Measurements in the Carotid and Femoral Artery as an Indicator of Symptomatic Coronary Atherosclerosis
}

\author{
A. Šrámek ${ }^{a}$ J.H.C. Reiber ${ }^{b}$ F.R. Rosendaala,c \\ aDepartment of Clinical Epidemiology, bDepartment of Radiology, ${ }^{\circ}$ Hemostasis and Thrombosis Research Center, \\ Leiden University Medical Center, Leiden, The Netherlands
}

For editorial comment see p. 242

\section{Key Words}

Intima-media thickness · Atherosclerosis - Carotid artery $\cdot$ Femoral artery $\cdot$ Ultrasound

\begin{abstract}
Background: Ultrasonographically determined intimamedia thickness of peripheral arteries is frequently used as an indicator of generalized and coronary atherosclerosis. Generally, the carotid artery is used. Measurements in the femoral artery have received little attention. Objective: In this study we investigated which of the ultrasonographically determined intima-media thickness measurements in either the common carotid artery, the carotid bulb, the common femoral artery or the superficial femoral artery is the best indicator for clinical coronary atherosclerosis. Methods: We determined the intima-media thickness in the common carotid artery, the carotid bulb, the common femoral artery and in the superficial femoral artery by B-mode ultrasonography in 78 patients with clinically proven severe coronary atherosclerosis and in 47 age-matched population controls. The odds ratio for the presence of coronary atherosclerosis was determined for every quintile of the intima-media thickness measurements in the arteries. Furthermore receiver operating characteristic (ROC) curves were constructed for the arteries to visualize the discriminating power of the measurements in these arteries. Results:
\end{abstract}

\begin{tabular}{ll}
\hline KARGER & O 2001 S. Karger AG, Basel \\
Fax+41613061234 & 1422-9528/01/0015-0249\$17.50/0 \\
$\begin{array}{l}\text { E-Mall karger@karger.ch } \\
\text { www. karger.com }\end{array}$ & $\begin{array}{l}\text { Accessible online at: } \\
\text { www. karger.com/journals/hed }\end{array}$
\end{tabular}

For every quintile, the odds ratios (for the presence of clinical coronary atherosclerosis) of the measurements were the highest in the carotid bulb (range 3.7-7.1) and in particular in the common femoral artery (9.8-27.9). In spection of the ROC curves showed that the test performance (i.e. sensitivity and specificity) to discriminate between individuals with clinical coronary atherosclerosis and the population controls was best for the femoral artery. The curves of the other three arteries were similar. Conclusion: The results of our study indicate that intima-media thickness measurements in the common femoral artery are a better indicator of coronary atherosclerosis than in the other three arteries.

Copyright $(\subseteq 2001$ S. Karger AG, Basel

\section{Introduction}

Intima-media thickness of peripheral arteries determined by B-mode ultrasonography is often used as an indicator of generalized and coronary atherosclerosis. It is mainly used in cross-sectional studies but recently also in clinical trials $[1,2]$. Ultrasonographically determined intima-media thickness of superficial arteries has proven to be accurate $[3,4]$ and reproducible [5]. Numerous studies found a clear relation between ultrasonographically determined intima-media thickness and established risk factors of cardiovascular disease, such as serum cholesterol

Prof. Dr. F.R. Rosendaal

Department of Clinical Epidemiology CO-P46

Leiden University Medical Center, PO Box 9600

NL-2300 RC Leiden (The Netherlands)

E-Mail F.R.Rosendaal@lumc.nl 
levels and blood pressure [6-8]. Furthermore intimamedia thickness in the carotid artery proved to be a good indicator of the extent of atherosclerosis in the coronary and other peripheral arteries $[9,10]$. Recent studies showed that intima-media thickness in the carotid arteries can even be used as a predictor for future cardiovascular events [11, 12].

In most of the studies in which intima-media thickness measurements were used as an indicator, the measurements were performed in one or more segments of the carotid artery (i.e. common carotid artery, carotid bifurcation and internal carotid artery). Even though the femoral artery is as well accessible by ultrasonography as the carotid artery, measurements in the femoral artery have received little attention. Only a few studies compared intima-media thickness in the carotid and femoral artery to the extent and severity of coronary atherosclerosis [13, 14]. The results of these studies suggest that intima-media thickness in the femoral artery compared to the carotid artery is a superior indicator for the extent and severity of coronary atherosclerosis.

In this study we measüred intima-media thickness in the common carotid artery, the carotid bulb, the common femoral artery and in the superficial femoral artery and examined the association of the measurements in these arteries with the presence of symptomatic coronary atherosclerosis. Furthermore we investigated the power of wall thickness measurements in the four arterial segments to discriminate between individuals with clinically proven coronary atherosclerosis and population controls with no symptomatic coronary heart disease.

\section{Methods}

\section{Subjects}

In this study we included 78 male patients who had undergone coronary bypass graft surgery and 47 age-matched male population controls without clinical signs of coronary heart disease. The coronary bypass patients were treated with oral anticoagulants after surgery and were selected from the archives of the Leiden Anticoagulant Clinic. The group of population controls consisted of 34 healthy age-matched friends or neighbours of the coronary bypass patients and 13 age-matched individuals who received temporary oral ant1coagulant treatment because of an orthopaedic condition, such as orthopaedic surgery or a fracture (selected from the archives of the Leiden Antıcoagulant Clınıc). All population controls were asked to fill out a translated version of the questionnaire of Rose et al. [15] to exclude individuals with clinical signs of coronary atherosclerosis. The study was approved by the Medical Ethics Committee of the Leiden University Medical Center and all individuals gave their informed consent.
Measurement of the Intıma-Media Thickness

Intıma-media thickness measurements were determined in the far walls of the common carotid artery, the carotid bulb, the common femoral and superficial artery A detaled description of the technıque is given elsewhere [5]. In brief, we used an Aloka SSD 1200 ultrasound machine with a $7.5-\mathrm{MHz}$ linear transducer to visualize the intima-media complex in the far wall of the arteries The images were frozen during the R-phase of the cardiac cycle using an ECGtriggering device that was attached to the ultrasound machine. Subsequently, two images of the arteries on each side were recorded on a S-VHS video tape and later digitalized and saved on a CD recordable. At a later stage, the images were loaded into a personal computer with a cardiovascular measurement system [16]. S1x measurements of the intima-media complex as defined by Pignolı et al. [3] were performed for every image. All measurements were made in the far wall. The measurements in the common carotid artery were performed in the area $2 \mathrm{~cm}$ proximal from the carotid bulb. The measurement area in the carotid bulb was defined as the area $1 \mathrm{~cm}$ proximal from the flow divider of the carotid bifurcation. In the femoral artery, the measurements were made $2 \mathrm{~cm}$ proximal from the site where the common femoral artery splits into the deep and superficial femoral branch The measurement area of the superficial femoral artery was defined as the area $2 \mathrm{~cm}$ distal from its origin The measurements in all four images of every arterial segment (left and right side combined) were averaged, resulting in a single mean intimamedia thickness of the common carotid artery, the carotıd bulb, the common femoral artery and the superficial femoral artery. All image acquisitions and measurements were performed by one investigator (A.S.). Durnng the actual measurements, the investigator was blinded to the identity of the subjects

Analysis

The distribution of the intıma-media thickness of all arterial segments proved to be positively skewed and the data were therefore transformed logarithmically prior to the analysis. To determme which artery is the best indicator for coronary atherosclerosis and whether increased intima-media thickness is related to the presence of clinical signs of coronary atheroscleiosis, we divided the distribution of the thickness of each arterial segment into quintiles Subsequently, we used the boundaries of each quintile as a cut-off point to determine the odds ratio of such a cut-off point for the presence of clinical coronary atherosclerosis. For these analyses the first quintule was used as the reference value. To determine the discriminating power of the intıma-media thickness of each artery on a contınuous scale, we visualized the test characteristics by using a receiver operating characteristics (ROC) curve $[17,18]$, a plot of the true positive (1.e. sensitivity) fraction against the false-positive fraction ( 1 e. 1 specificity) for varying cut-off points The area under the line in such a graph can be regarded as a measure of the discriminating power of the test.

\section{Results}

The group of population controls (mean age: 63 , range: 33-76) was slightly younger than the coronary bypass graft patients (mean age: 66 , range: $42-84$ years). Figure 1 shows the comparison of intima-media thickness in the

Srámek/Reiber/Rosendaal 
Common carotid artery

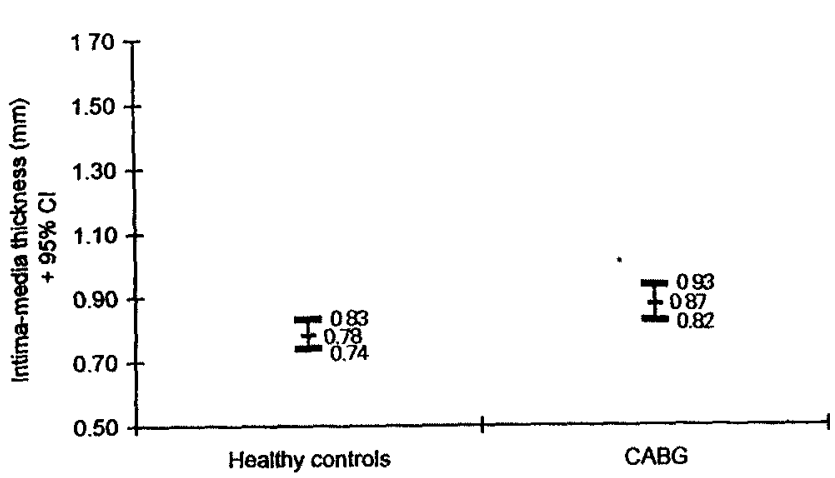

Common femoral artery

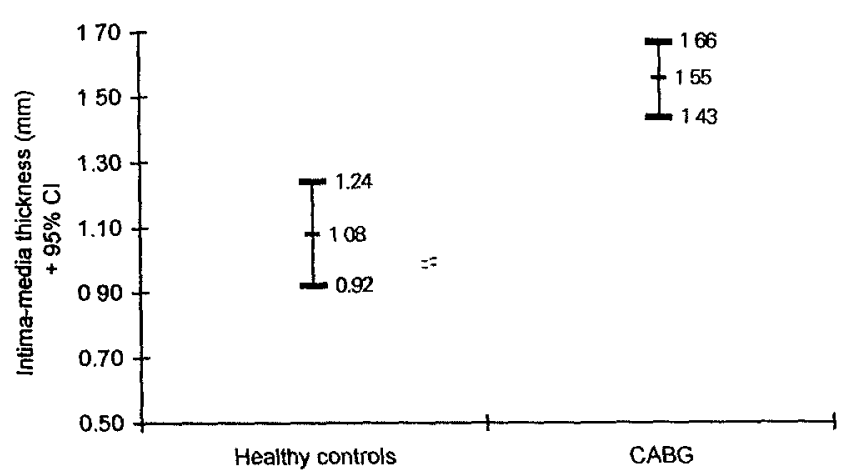

\section{Carotid bulb}

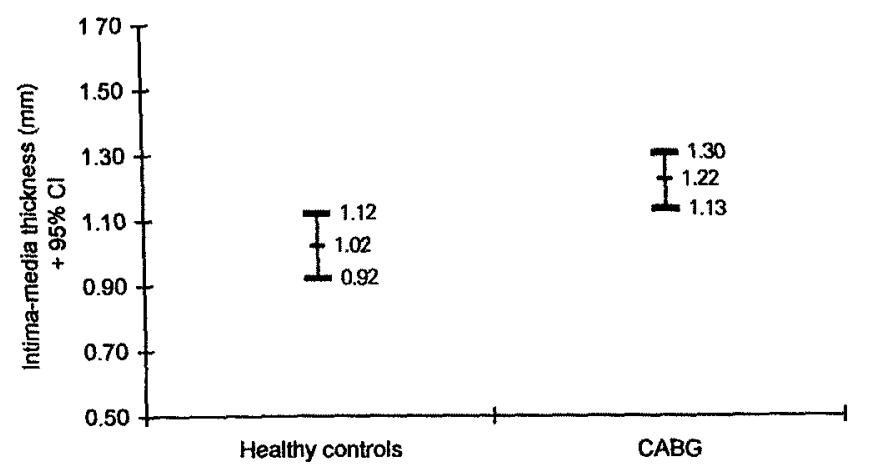

Superficial femoral artery

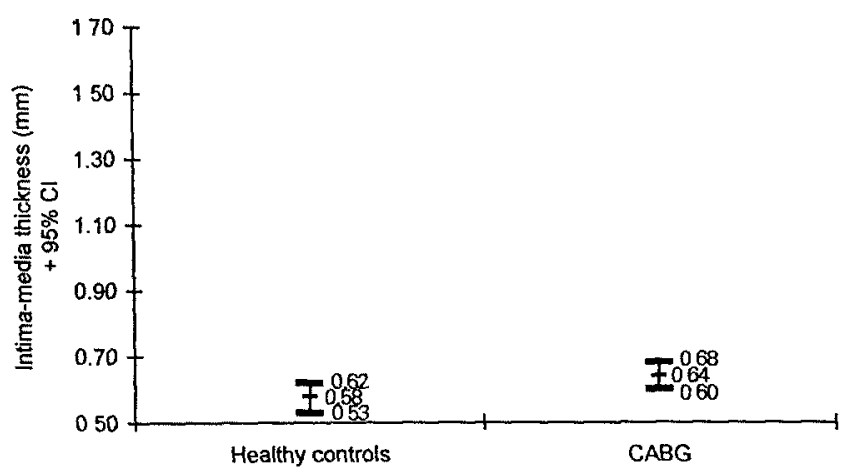

Fig. 1. Visual comparison of the intima-media thickness in the common carotıd artery, the carotid bulb, the common femoral artery and the superficial femoral artery between patients with clinically proven coronary atherosclerosis and population controls without symptomatic coronary heart disease. The mean and $95 \% \mathrm{CI}$ of the intima-media thickness is indicated by horizontal dashes.

four arterial segments between the patients with clinical atherosclerosis and the population controls. The largest difference in intima-media thickness was found for the common femoral artery (geometric mean difference: $0.40 \mathrm{~mm}, 95 \% \mathrm{CI}: 0.26-0.53$ ). Within the carotid artery, a higher difference in the carotid bulb was found (geometric mean difference: $0.17 \mathrm{~mm}, 95 \mathrm{CI}: 0.070-0.28$ ) than in the common carotid artery (geometric mean difference: $0.095 \mathrm{~mm}, 95 \% \mathrm{CI}: 0.016-0.17)$ between the patients and population controls. The difference of arterial wall thickness in the superficial femoral artery (geometric mean difference: $0.10 \mathrm{~mm}, 95 \% \mathrm{CI}: 0.020-0.19)$ turned out to be similar to the one in the common carotid artery.

To study whether an increasing intima-media thickness in the arterial segments is related to the presence of clinical coronary atherosclerosis we divided the measurements into quintiles of the intima-media thickness in the four arterial segments. Subsequently, we used each quintile as a cut-off point to determine the odds ratio of that cut-off point for the presence of clinical atherosclerosis. The first quintile was used as reference. Table 1 shows the cut-off points based on the quintiles and the accompanying odds ratios. For all arteries, we found increasing odds ratios with increasing values of the cut-off points. The odds ratios determined for the carotid bulb (range: 4.0-7.1) and in particular for the common femoral artery (range: 9.8-27.9) were the highest for every cut-off point. For lower cut-off points the odds ratios for the common carotid artery (range: $2.1-3.4$ ) and the superficial femoral artery (range: $1.5-5.9$ ) were similar. But for the higher 
Table 1. Odds ratios for symptomatic coronary atherosclerosis for increasing cut-off points of the intima-media thickness in the common carotid artery, the carotid bulb, the common femoral artery and the superficial femoral artery

\begin{tabular}{llcl}
\hline Artery & Cut-off point, mm & Odds ratio & $95 \% \mathrm{CI}$ \\
\hline Common & 0.69 & 2.1 & $0.8-5.5$ \\
carotid artery & 0.76 & 3.0 & $1.1-8.5$ \\
& 0.85 & 2.5 & $0.8-7.7$ \\
& 0.96 & 3.4 & $0.9-13.8$ \\
\hline Carotid bulb & 0.84 & 4.0 & $1.5-11.0$ \\
& 1.00 & 4.6 & $1.6-13.4$ \\
& 1.16 & 7.1 & $2.2-24.2$ \\
\hline Common & 1.42 & 7.1 & $1.7-31.7$ \\
femoral artery & 0.84 & 9.8 & $3.0-33.4$ \\
& 1.15 & 15.2 & $4.4-56.3$ \\
\multicolumn{1}{c}{} & 1.47 & 17.3 & $4.5-72.4$ \\
\hline Superficial & 1.77 & 27.9 & $4.9-190.7$ \\
femoral artery & 0.49 & 1.5 & $0.6-4.1$ \\
& 0.56 & 2.0 & $0.7-5.8$ \\
& 0.60 & 3.0 & $0.9-9.8$ \\
& 0.69 & 5.9 & $1.2-33.4$ \\
\hline
\end{tabular}

cut-off points the superficial femoral artery proved to be superior in comparison to the common carotid artery as an indicator of coronary atherosclerosis.

To determine the discriminating power of the intimamedia thickness measurements in the four arterial segments for the presence of clinical coronary atherosclerosis, ROC curves were constructed for every arterial segment (fig. 2). In general, better test performance is indicated by a ROC curve that is higher and more to the left in the ROC space, or in other words with a higher area under the curve (maximum $=1$ ) $[17,18]$. Inspection of the curves shows that the test performance (i.e. sensitivity and specificity) of intima-media thickness measurements to differentiate between individuals with clinical coronary atherosclerosis and population controls was best for the common femoral artery (calculated area under the curve: 0.79 ). The curves and the calculated areas under the curves of the other three arteries were similar.

\section{Discussion}

In this study we investigated which of the intimamedia thickness measurements in either the common carotid artery, the carotid bulb, the common femoral artery or the superficial femoral artery best predict the presence of clinical coronary atherosclerosis. We studied the discriminating power of early atherosclerotic measurements in these arterial segments to differentiate between subjects with and without clinical signs of coronary atherosclerosis. The intima-media thickness in the common femoral artery best reflects the atherosclerotic state in the coronaries, followed by the measurements in the carotid bulb. Intima-media thickness measurements in the common carotid artery turned out to have the lowest discriminating power.

Intima-media thickness measurements in peripheral arteries determined by B-mode ultrasonography are frequently used in studies as an indicator of coronary and generalized atherosclerosis $[1,2,6-8,19,20]$. Using ultrasonographically determined intima-media thickness measurements as an indicator has some important advantages: the examination is cheap, easy and fast to perform, it is non-invasive and the technique has proven to be very reproducible $[5,21]$. One might, however, wonder whether intima-media thickening truly represents an early stage in atherogenesis or just a reaction to haemodynamic factors. Numerous studies showed a clear relation of intimamedia thickness in peripheral arteries with the established risk factors of atherosclerosis [6-8]. Furthermore it was shown that intima-media thickness measurements in peripheral arteries reflect the extent of atherosclerosis well in other peripheral arteries and the coronary arteries [9, 10]. In two recent studies, it was proven that intimamedia thickness measurements in the carotid artery may be used as a predictor of future coronary events $[11,12]$. The results of our study confirm that intima-media thickness measurements in peripheral arteries can be used as a marker for the presence of symptomatic coronary atherosclerosis. Since the carotid artery is well accessible by high-frequency ultrasonography, the carotid artery is usually used as the site to quantify the intima-media thickness in most studies. Although the femoral artery is as well accessible for ultrasonography, it is generally not used to measure vessel wall thickness.

The results of this study are in accordance with the results of a recent study performed by Lekakis et al. [13]. In their study the atherosclerotic vessel wall measurements in the femoral artery proved to be a better indicator of coronary atherosclerosis determined by coronary angiography than measurements in the common carotid artery, the carotid bulb or the internal carotid artery. Similar results were found in a study by Megnien et al. [14] in which the femoral artery proved to be superior to the common carotid artery as a marker of coronary atherosclerosis determined by ultrafast computer tomography. 

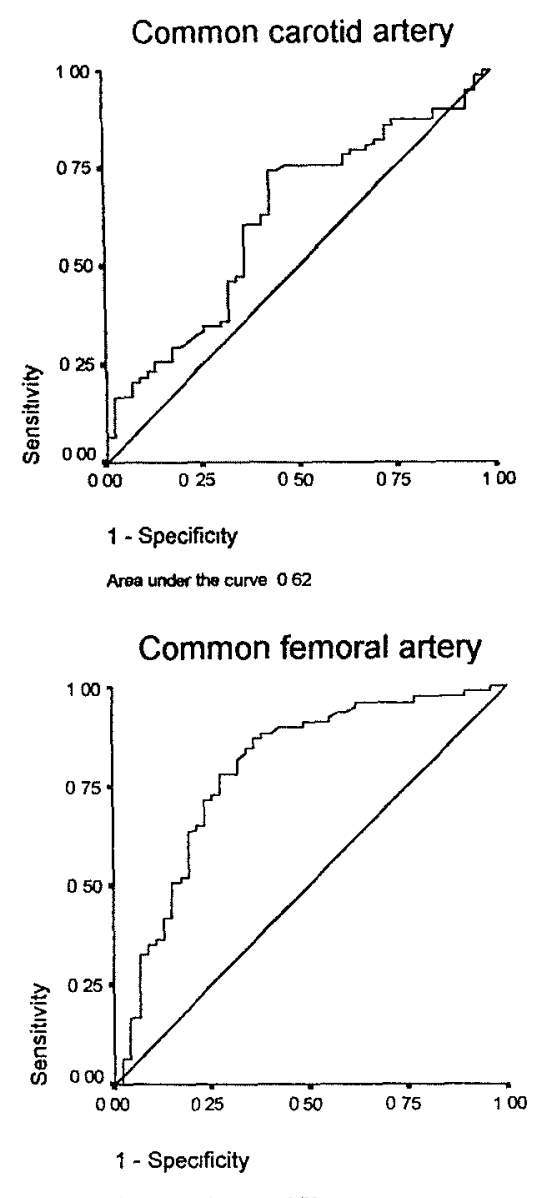

Area under the curve 079
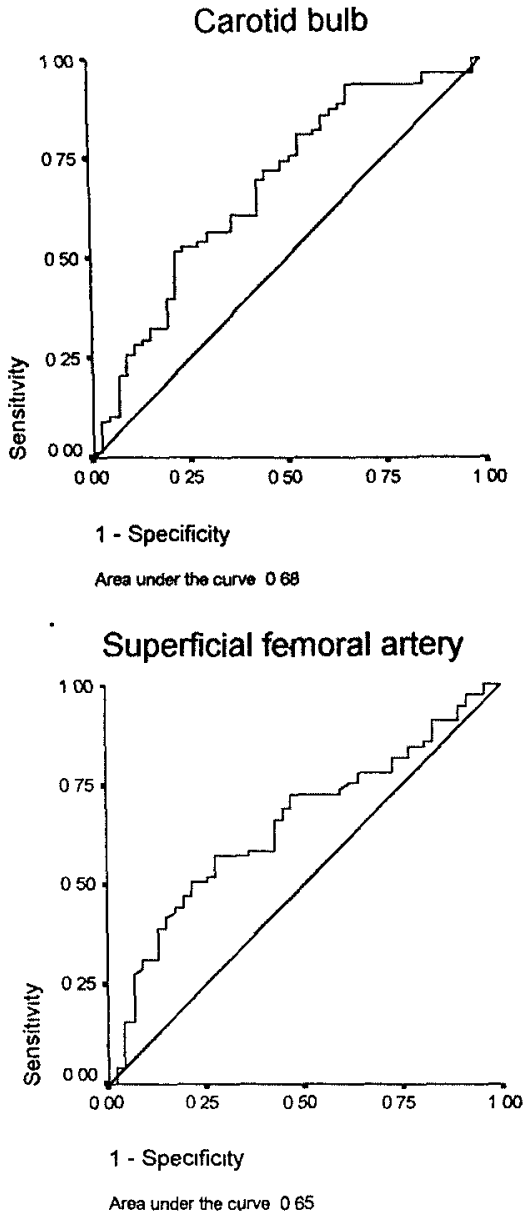

Fig. 2. Plot of the true-positive fraction (sensitivity) against the false-positive fraction ( 1 - specificity) for the intima-media thickness measurements in the common carotid artery, the carotid bulb, the common femoral artery and the superficial femoral artery based on the 78 patients with coronary atherosclerosis and 47 population controls without symptomatic coronary heart disease. The area under the curve (maximum $=1$ ) is an indication of the discriminating power of the intima-media thickness measurements as a test to differentiate between individuals with clinical coronary atherosclcrosis and individuals without symptomatic coronary heart disease.
In another study [22] in which the measurements in the common carotid artery, the carotid bulb and the common femoral artery were compared, the thickness in the carotid bulb turned out to be the best indicator for the extent of coronary atherosclerosis. In that study, however, only a small number of subjects were included.

We compared early atherosclerotic vessel wall changes in individuals with coronary atherosclerosis to population controls without obvious coronary atherosclerosis. The presence of symptomatic coronary atherosclerosis in the population controls was excluded by a translated version of the questionnaire of Rose et al. [15]. This questionnaire discriminates between individuals with and without symptomatic coronary atherosclerosis; however, it does not discriminate between the presence and absence of actual atherosclerotic plaques, but only those that are symptomatic. Regarding the age of the subjects, it is very probable that a number of the population controls had non-symptomatic atherosclerotic changes in the coronaries and therefore were not completely free from atherosclerosis. On the other hand, it is expected that on average the extent of coronary atherosclerosis in coronary bypass graft patients is much larger than in population controls without symptomatic coronary heart disease.

Our study indicates that intima-media thickness measurements in the carotid bulb and in particular in the femoral artery are a better indicator of coronary atherosclerosis than measurements in the common carotid artery and superficial femoral artery. A plausible explanation might be that the haemodynamic conditions in the common femoral artery and carotid bulb are more closely related to those in the coronary arteries than the conditions in the common carotid artery and the superficial femoral artery which are more straight arterial segments. 
Although atherogenesis usually is a generalized process involving most arteries, as confirmed by a recent study [P. Bucciarelli: Arterial intima-media thickness and its relationship with cardiovascular disease and atherosclerosis: A possible contribution of medium-sized arteries; unpubl. data], it is generally acknowledged that some arterial segments, in particular those with curves and near bifurcations, are more prone to develop earlier and more extensive atherosclerotic plaques.

The choice which site should be used as a marker of coronary atherosclerosis should not only be based on the strength of its relation to the extent of coronary atherosclerosis. Other test characteristics, such as reproducibility of the measurements, should also be taken into account. In a recent study we found that in comparison to the other three arterial sites the measurements in the common carotid artery were best reproducible and least affected by progressed atherosclerotic changes in the ar- terial segment [5]. These results and the results of the present study suggest that when intima-media thickness measurements are performed to detect the presence of coronary atherosclerosis, the femoral artery is the recommended site to perform the measurements. On the other hand, if progression of atherosclerotic changes has to be evaluated, as in clinical trials, measurements in the common carotid artery are most recommended. Since the ultrasound examination is easy and fast, the best choice is probably to perform the measurements in more than one arterial segment (e.g. common carotid artery, carotid bulb and common femoral artery).

\section{Acknowledgments}

This study was funded by the Netherlands Heart Foundation (No 93110 ).

\section{References}

1 Tang R, Hennig M, Thomasson B, Scherz R, Ravinetto R, Catalını R, Rubba P, Zanchettı A, Bond $M G$ Baseline reproducibility of B-mode ultrasonic measurement of carotid artery intma-media thıckness The European Lacıdipinc Study on Atherosclerosis (ELSA) J Hypertens 2000,18 197-201

2 Koshiyama H, Tanaka S, Minamıkawa J Eftect of calcium channel blocker amlodipine on the intimal-medial thickness of carotid arterial wall in type 2 diabetes J Cardiovasc Pharmacol 1999,33 894-896

3 Pignoli P, Tremoli E, Polı A, Oreste P, Paolett $R$ Intimal plus medial thickness of the arterial wall A direct measurement with ultrasound imaging Circulation 1986,74 1399-1406

4 Wong M, Edelstein J, Wollman J, Bond MG Ultrasonic-pathological comparison of the human arterial wall Verification of intima-media thickness Arterioscler Thromb 1993,13 482486

5 Sramek A, Bosch JG, Reiber JHC, van Oostaayen J, Rosendaal FR Ultrasound assessment of atherosclerotic vessel wall changes $\mathrm{Re}-$ producibility in carotid and femoral arteries Invest Radiol 2000,35 699-707

6 Sosef MN, Bosch JG, van Oostayen J, Visser T, Reiber JH, Rosendaal FR Relation of plasma coagulation factor VII and fibrinogen to carotid artery intıma-media thıckness Thromb Haemost 1994,72 250-254

7 Salonen R, Salonen JT Determinants of carotid intima-media thickness A population-based ultrasonography study in eastern Finnish men J Intern Med 1991,229 225-231
8 Heiss G, Sharrett AR, Barnes R, Chambless LE, Szklo M, Alzola C Carotid atherosclerosis measured by B-mode ultrasound in populations Associations with cardiovascular risk factors in the ARIC study Am J Ep1demiol 1991,134250-256

9 Bots ML, Hofmann A, Grobbee DE Common carotıd intıma-media thickness and lower extremity arternal atherosclerosis The Rotterdam Study Arterioseler Thromb 1994,14 1885 1891

10 Burke GL, Evans GW, Rilcy WA, Sharrett AR, Howard G, Barnes RW, Rosamond W, Crow RS, Rautaharju PM, Herss G Arterial wall thickness is associated with prevalent cardiovascular disease in middlc-aged adults The Atherosclerosis Risk in Communities (ARIC) Study Stroke 1995,26 386-391

11 Bots ML, Hoes AW, Koudstaal PJ, Hofman A Grobbec DE Common carotid intıma-media thickness and risk of stroke and myocardial infarction The Rotterdam Study Circulation 1997,96 1432-1437

12 O'Leary DH, Polak JF, Kronmal RA, Manolio TA, Burke GL, Wolfson SKJ Carotıd-artery intima and media thickness as a risk factor for myocardial infarction and stroke in older adults $\mathrm{N}$ Engl J Med 1999,340 14-22

13 Lekakıs JP, Papamichael CM, Cimponeriu AT, Stamatelopoulos KS, Papaıannou TG, Kanakakıs J, Alevızakı MK, Papapanagıtou A, Kalofoutis AT, Stamatelopoulos SF Atherosclerotic changes of extracoronary arterics are assocrated with the extent of coronary atherosclerosis Am J Cardiol 2000,85 949-952
14 Megnien JL, Simon A, Gariepy J, Denaric N, Cocaul M, Linhart A, Levenson J Preclinical changes of extracoronary arterial structures as indicators of coronary atherosclerosis in men J Hypertens 1998,16 157-163.

15 Rose GA, Blackburn H, Gillum RF, Pruneas RJ Cardiovascular survey methods Geneva World Health Organisation, 1982

16 Koning G, Reiber JH, von Land CD, Loots G, van Meurs B Advantages and limitations of two software calipers in quantitative coronary arterography Int J Card Imaging 1991,7 1530

17 Metz CE Basic principles of ROC analysis Semun Nucl Med 19788 283-298

18 Turner DA An intuitive approach to receiver operatıng characteristic curve anaiysis $\mathrm{J}$ Nucl Med 1978,19 213-220

19 Wendelhag I, Wiklund O, Wikstrand J Arterial wall thickness in familial hypercholesterolemia Ultrasound measurement of intima-media thickness in the common carotid artery Arterioscler Thromb 1992,12 70-77

20 Grobbee DE, Bots ML Carotıd artery intimamedia thickness as an indicator of gencralized atherosclerosis J Intern Med 1994,236 567573

21 Kanters SD, Algra A, van Leeuwen MS, Banga JD Reproducibility of in vivo carotid intimamedia thickness measurcments A review (rcview) Stroke 1997,28 665-671

22 Hulthe J, Wikstrand J, Emanuelsson H, W1klund $\mathrm{O}$, de Feyter PJ, Wendelhag I Atherosclerotic changes in the carotid artery bulb as measured by B-mode ultrasound are associated with the extent of coronary atherosclerosis Stroke 1997,28 1189-1194 